\title{
ESPÉCIES VEGETAIS PARA PRODUÇÃO OUTONAL DE COBERTURA MORTA DE SOLO, SEM IRRIGAÇÃO, NA REGIÃO TROPICAL DE SÃO CARLOS, SP, BRASIL
}

\author{
Odo Primavesi ${ }^{1}$ \\ Ana Cândida Primavesi ${ }^{1}$
}

\section{RESUMO}

Com o objetivo de avaliar espécies vegetais com potencial para produzir no mínimo 6 t/ha de massa orgânica para a cobertura morta de solo, em plantio de março, em região com inverno seco, para atender áreas de plantio direto de milho ou sorgo para silagem, que praticamente não deixam resíduos, foram conduzidos experimentos na Embrapa Pecuária Sudeste, em Latossolo Vermelho-Amarelo Álico típico (LVAa) e Latossolo Vermelho Distrófico típico (LVd), textura arenosa, localizado na latitude de $21^{\circ} 57^{\prime} \mathrm{S}$, e longitude de $47^{\circ} 50^{\prime} \mathrm{W}$ e uma altitude de $850 \mathrm{~m}$, apresentando clima tropical de altitude. Foram avaliados especialmente Crotalaria juncea, Crotalaria paulina, Mucuna aterrima, Mucuna cinerea, Canavalia ensiformis, Dolichus lablab, Helianthus anuus, Lupinus albus, Raphanus sativus, Sorghum bicolor, Penissetum americanum e Zea mays. O delineamento experimental foi o de blocos ao acaso com três repetições, em cada solo. Os blocos apresentaram graus de fertilidade conhecidos de $\mathrm{Ca}, \mathrm{K}$ e P. O milho apresentou maior potencial em produção de matéria seca para a cobertura de solo que as leguminosas. Estas apresentaram no máximo $50 \%$ do mínimo requerido de $6 \mathrm{t} / \mathrm{ha}$. Girassol e eventualmente mucunacinza podem ser considerados para um esquema rotacional. $O$ tipo de solo, o nivel de fertilidade e a presença de cobertura morta interferi-

Embrapa - Pecuária do Sudeste, Caixa Postal 339, 13560-970 São Carlos, SP, Email: odo@cppse.embrapa.br 
ram na avaliação das espécies vegetais. Outros materiais necessitam ser avaliados para atender à demanda mínima por palhada nos trópicos.

Palavras-chave: cobertura morta, adubo verde, plantio de outono, seca, safrinha.

\section{ABSTRACT}

\section{PLANT SPECIES FOR AUTUMN MULCH PRODUCTION, WITHOUT IRRIGATION, IN SÃO CARLOS, SP, BRAZIL.}

With the goal to produce at least 6 tha of dry organic matter, as mulch for sandy soils, in the dry autumn-winter period, in the latitude.of $21^{\circ} 57^{\prime} \mathrm{S}$, longitude of $47^{\circ} 50^{\prime} \mathrm{W}$ and altitude of $850 \mathrm{~m}$, under a tropical altitude climate, different plant species were evaluated in the experimental area of the Southeastern Cattle Research Center of EMBRAPA, on Oxisols. The species were Crotalaria juncea, C. spectabilis, C. breviflora, Mucuna aterrima, Mucuna cinerea, Canavalia ensiformis, Cajanus cajan, Dolichus lablab, Stylosanthes guianensis, Glycine max, Leucaena leucocephala, Sorghum bicolor, Penissetum americanum and Zea mays. The experimental design presented three replications in randomized blocks, with known, $\mathrm{Ca}, \mathrm{K}$ and $\mathrm{P}$ fertility levels, in both soils. The grasses showed a bigger potential in yielding dry matter for mulch purposes then the legumes. These yielded only $50 \%$ of the established goal of 6 t/ha. Sunflower and Mucuna cinerea could be considered for rotational sequences. The soil type, the fertility level and mulching interfered in the evaluation of the species. Other species need evaluation to reach the established goal of dry matter for mulching in the tropics.

Key words: mulch, green manure, fall seeding, dry season.

\section{INTRODUÇÃO}

Para manter ou melhorar a produtividade de solos de cerrados 


\section{}

arenosos e de baixa fertilidade, em sistemas intensivos de produção animal, especificamente em áreas exclusivas de produção de gramíneas para silagem, não irrigadas e em plantio direto, é necessário garantir o retorno de material orgânico ao solo e propiciar uma cobertura protetora da superfície do solo contra a ação erosiva da chuva e o aquecimento excessivo pelo sol, pelo menos à semeadura até a cobertura do solo pela cultura principal. Este material orgânico poderá constituir fonte adicional de nitrogênio. Faltam referências sobre espécies vegetais que podem ser cultivadas a partir de março, abaixo do paralelo 23, em região com clima tropical de altitude, que apresenta período seco hibernal definido e com elevada taxa de evaporação.

Das poucas referências existentes, pode-se citar a de Burle et al. (1992), Abboud \& Duque (1993) e Amabile et al. (1993) que procuraram as leguminosas mais produtivas, especialmente como fonte orgânica de N para milho nos cerrados de Brasília, e de Pitol (1993), visando a cobertura viva de solo, no Mato Grosso do Sul. Castro (1993) sugeriu diversas espécies vegetais plantadas no outono-inverno, para o Estado de São Paulo. No Goiás, recomendam culturas "safrinha" como de milho, girassol, sorgo, aveia-preta e milheto (Scaléa, 1992). Houve informação verbal sobre o uso com sucesso da mucuna-cinza após a cultura do milho, no sul do Estado de Goiás.

Com a finalidade de atender a demanda regional por sugestão de opções de espécies vegetais que possam ser conduzidas em áreas de milho ou sorgo para silagem, sem possibilidade de irrigação, foi planejada uma série de avaliações de materiais vegetais com potencial para produzir no mínimo 6 t/ha de material orgânico para cobertura morta do solo, em áreas submetidas ao uso da técnica do plantio direto (Castro, 1993).

\section{MATERIAL E MÉTODOS}

Os experimentos foram realizados na área experimental do Embrapa Pecuária Sudeste, fazenda Canchim, na região de São Carlos, $\mathrm{SP}$, latitude $21^{\circ} 57^{\prime} 42^{\prime \prime} \mathrm{S}$, longitude $47^{\circ} 50^{\prime} 28^{\prime \prime} \mathrm{W}$ e altitude de $850 \mathrm{~m}$, 
com clima tropical de altitude. Foram utilizados um Latossolo Vermelho-Amarelo Álico típico (LVAa) e um Latossolo Vermelho Distrófico típico (LVd), cujas principais características químicas na camada de 0-20 $\mathrm{cm}$ e físicas no perfil, encontram-se, respectivamente, nas Tabelas 1 e 2.

As características do tempo ocorridas nos períodos vegetativos aparecem nas Tabelas 3 e 4.

Os tratamentos consistiram no plantio de espécies vegetais, em especial leguminosas, para avaliar seu potencial de produção de matéria seca, com a finalidade de permitir o sistema de plantio direto de milho para silagem na palhada. Foi realizado o plantio no verão para avaliar a intensidade de queda de produção em relação ao plantio de outono, época de maior interesse. No segundo período de avaliação, introduziu-se o tratamento cobertura morta de solo para verificar o comportamento dos adubos verdes em áreas com esta característica superficial.

Como havia gradiente de fertilidade nas áreas experimentais, foi utilizada a estratégia de realizar a calagem e a adubação mineral específica por bloco experimental, de maneira a ocorrerem, nos blocos 1, 2 e 3, saturações por base de 25 (ou original, no LVAa), 50 e $75 \%$, e relações $\mathrm{Ca}: \mathrm{K}$ de 9:1, de modo a permitir observação sobre potencial comportamento diferenciado dos materiais testados. No período 1992/93, em ambos plantios, no LVAa foram aplicados $0,8,2,4$ e 4,1 t/ha calcário dolomítico, com PRNT de 76,7\% e PN de 104,1\%, e ao plantio, a lanço, 0,85 e $170 \mathrm{~kg} / \mathrm{ha} \mathrm{de} \mathrm{K}_{2} \mathrm{O}$ na forma de $\mathrm{KCl}$, e 60,120 e $180 \mathrm{~kg} / \mathrm{ha}$ de $\mathrm{P}_{2} \mathrm{O}_{5}$ na forma de superfosfato triplo. No LVd foram aplicados $0,1,3,2 \mathrm{t} / \mathrm{ha}$ de calcário, 94, 141 e $254 \mathrm{~kg} / \mathrm{ha}$ de $\mathrm{K}_{2} \mathrm{O}, 60,120,180 \mathrm{~kg} / \mathrm{ha}$ de $\mathrm{P}_{2} \mathrm{O}_{5}$. No periodo 1993/94, em ambos plantios, no LVAa foram aplicados $0,7,2,7 \mathrm{e}$ 3,8 tha calcário dolomítico, com PRNT de $76,7 \%$ e PN de $104,1 \%$, e ao plantio, a lanço, 19,186 e $343 \mathrm{~kg} / \mathrm{ha}$ de $\mathrm{K}_{2} \mathrm{O}$ na forma de $\mathrm{KCl}, \mathrm{e} 60,120$ e $180 \mathrm{~kg} /$ ha de $\mathrm{P}_{2} \mathrm{O}_{5}$ na forma de superfosfato triplo. No LVd foram aplicados 0, 0,5 e 2,4 t/ha de calcário, 94, 141 e $340 \mathrm{~kg} / \mathrm{ha}$ de $\mathrm{K}_{2} \mathrm{O}, 60,120$, $180 \mathrm{~kg} / \mathrm{ha}$ de $\mathrm{P}_{2} \mathrm{O}_{5}$. Em 1995 foi realizada a calagem para atingir saturação por bases de $50 \%$. Os fertilizantes foram incorporados com enxada rotativa no dia da semeadura. Não foi utilizado nitrogênio nem qualquer tipo de inoculante, nas duas áreas, reproduzindo a realidade de campo. 
Tabela 1. Características químicas dos solos.

\begin{tabular}{|c|c|c|c|c|c|c|}
\hline \multirow{2}{*}{ Características } & \multicolumn{3}{|c|}{----_-LVAa-_...-- } & \multicolumn{3}{|c|}{ 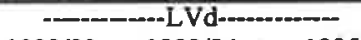 } \\
\hline & $1992 / 93$ & $1993 / 94$ & 1995 & $1992 / 93$ & $1993 / 94$ & 1995 \\
\hline pH-água $(1: 2,5)$ & 4,5 & 5,1 & 4,8 & 5,2 & 5,7 & 5,5 \\
\hline $\mathrm{H}-\mathrm{CaCl}_{2}(1: 2,5)$ & 3,9 & 4,2 & 4,0 & 4,4 & 4,8 & 4,6 \\
\hline Mat.orgânica, $\mathrm{g} \mathrm{dm}^{-3}$ & 12,0 & 10,0 & 10,0 & 15,0 & 17,0 & 15,0 \\
\hline p-resina, $\mathrm{mg} \mathrm{dm}^{-3}$ & 5,0 & 2,0 & 3,0 & 3,0 & 5,0 & 5,0 \\
\hline $\mathrm{K}^{+}, \mathrm{mmol}_{c} \mathrm{dm}^{-3}$ & 1,0 & 0,8 & 0,8 & 1,0 & 0,5 & 0,5 \\
\hline $\mathrm{Ca}^{2+}, \mathrm{mmol}_{\mathrm{c}} \mathrm{dm}^{-3}$ & 3,0 & 3,0 & 2,8 & 14,0 & 13,0 & 12,0 \\
\hline $\mathrm{Mg}^{2+}, \mathrm{mmol}_{c} \mathrm{dm}^{-3}$ & 2,0 & 2,0 & 1,7 & 8,0 & 7,0 & 6,0 \\
\hline $\mathrm{Al}^{3+}, \mathrm{mmol}_{\mathrm{c}} \mathrm{dm}^{-3}$ & 10,0 & 6,0 & 6,0 & 3,0 & 1,0 & 1,0 \\
\hline CTC, $\mathrm{mmol}_{\mathrm{c}} \mathrm{dm}^{-3}$ & 44,0 & 42,0 & 42,0 & 59,0 & 49,0 & 48,0 \\
\hline $\mathrm{v}, \%$ & 14,0 & 14,0 & 13,0 & 39,0 & 43,0 & 39,0 \\
\hline $\mathrm{m}, \%$ & 63,0 & 51,0 & 53,0 & 13,0 & 5,0 & 5,0 \\
\hline $\mathrm{Fe}, \mathrm{mg} \mathrm{dm}^{-3}$ & 47,0 & & & 61,4 & & \\
\hline $\mathrm{Mn}, \mathrm{mg} \mathrm{dm}^{-3}$ & 5,2 & & & 27,5 & & \\
\hline $\mathrm{Cu}, \mathrm{mg} \mathrm{dm}^{-3}$ & 0,8 & & & 1,7 & & \\
\hline $\mathrm{Zn}, \mathrm{mg} \mathrm{dm} \mathrm{m}^{-3}$ & 0,3 & & & 0,9 & & \\
\hline $\mathrm{B}, \mathrm{mg} \mathrm{dm}^{-3}$ & 0,1 & & & 0,4 & & \\
\hline
\end{tabular}

Análises conforme método IAC, descrito em Raij et al. (1987). Os valores foram obtidos de amostra composta de 20 subamostras.

Tabela 2. Características e propriedades físicas dos solos.

\begin{tabular}{|c|c|c|c|c|}
\hline \multirow{2}{*}{$\begin{array}{l}\text { Características } \\
\text { camada, } \mathrm{cm}\end{array}$} & \multicolumn{2}{|c|}{ - LVAa---- } & \multicolumn{2}{|c|}{-...-- LVd--.-- } \\
\hline & $0-20$ & $20-40$ & $0-20$ & $20-40$ \\
\hline Areia, $\mathrm{g} \mathrm{kg}^{-1}$ & 735 & 722 & 660 & 633 \\
\hline Silte, $\mathrm{g} \mathrm{kg}^{-1}$ & 9 & 10 & 76 & 69 \\
\hline Argila, $\mathbf{g ~ k g}^{-1}$ & 256 & 268 & 292 & 325 \\
\hline Densidade do solo, $\mathrm{Mg} \mathrm{m}^{-3}$ & 1,42 & 1,50 & 1,36 & 1,43 \\
\hline Total poros, $\%$ & 47,5 & 43,0 & 49,0 & 46,0 \\
\hline Macroporos, \% & 21,0 & 19,0 & 22,5 & 20,0 \\
\hline $\mathrm{CAD}, \mathrm{mm}$ & 15,0 & 13,0 & 17,0 & 19,0 \\
\hline
\end{tabular}

Análise granulométrica com método da pipeta, e determinação de curva característica de amostras indeformadas de solo. $\mathrm{CAD}=$ capacidade de armazenamento de água disponível, considerando tensão de $30,4 \mathrm{kPa}$. Valores médios de 6 amostras por camada.

As espécies vegetais e as respectivas quantidades de sementes utilizadas, no período 1992/93, foram: labe-labe (Dolichus lablab, cv. Rongai, 12 sem./m), guandu (Cajanus cajan, cv. EPAMIG 1822, e cv. EPAMIG 1679, 20 sem./m), estilosantes (Siylosanthes guianensis, cv. 
Tabela 3. Condições do tempo, no verão.

\begin{tabular}{|c|c|c|c|c|c|c|}
\hline \multirow{2}{*}{$\begin{array}{l}\text { Caracteristicas atmosféricas } \\
\text { Dias considerados }\end{array}$} & \multirow{2}{*}{$\begin{array}{l}1992 / 93 \\
90\end{array}$} & \multicolumn{5}{|c|}{ (1) $1993 / 94=4==$} \\
\hline & & 72 & 95 & 150 & 177 & 276 \\
\hline Chuvas, $\mathrm{mm}$ & 729 & 546 & 668 & 823 & 870 & 978 \\
\hline Evapotranspiraçăo potencial, $\mathrm{mm}$ & 450 & 346 & 480 & 681 & 771 & 1092 \\
\hline Déficit hidrico, $\mathrm{mm}$ & 29 & 15 & 24 & 40 & 59 & 229 \\
\hline Excedente hídrico, mm & 212 & 62 & 62 & 62 & 62 & 62 \\
\hline Temperatura média, ${ }^{\circ} \mathrm{C}$ & 22,9 & 22,8 & 23,4 & 22,9 & 22,4 & 20,9 \\
\hline Umidade relativa do ar média, \% & 79 & 80 & 81 & 80 & 79 & 74 \\
\hline Radiação global estimada, $\mathrm{kcal} \mathrm{cm}^{-2}$ & 50,2 & 39,9 & 54,7 & 81,3 & 92,5 & 135,8 \\
\hline
\end{tabular}

Tabela 4. Condições do tempo, no outono.

\begin{tabular}{|c|c|c|c|c|c|c|c|c|}
\hline \multirow{2}{*}{$\begin{array}{l}\text { Caracteristicas atmosféricas } \\
\text { Dias considerados }\end{array}$} & \multirow{2}{*}{$\begin{array}{l}1993 \\
113\end{array}$} & \multicolumn{4}{|c|}{-1994-...-. } & \multicolumn{3}{|c|}{$\ldots$} \\
\hline & & 69 & 9] & 116 & 175 & 96 & 139 & 168 \\
\hline Chuvas, mm & 323 & 181 & 195 & 275 & 303 & 279 & 326 & 326 \\
\hline Evapotranspiraçăo potencial, mm & 340 & 245 & 304 & 377 & 626 & 373 & 505 & 638 \\
\hline Deficit hídric & 23 & 50 & 79 & 104 & 271 & 69 & 142 & 263 \\
\hline Excedente hidrico, mm & 16 & 0 & 0 & 0 & 0 & 14 & 14 & 14 \\
\hline Temperatura média, ${ }^{\circ} \mathrm{C}$ & 19,9 & 21,6 & 20,6 & 19,9 & 20,0 & 20,5 & 20,2 & 20,5 \\
\hline Umidade relativa do ar média, \% & 79 & 78 & 77 & 75 & 61 & 78 & 77 & 75 \\
\hline Radiaçằo global estimada, $\mathrm{kcal} \mathrm{cm}^{-2}$ & 48,0 & 32,8 & 40,5 & 48,5 & 80,8 & 45,6 & 62,5 & 78,0 \\
\hline
\end{tabular}

Valores baseados em médias decendiais acumuladas nos períodos, a partir dos dados da Estação Meteorológica da Embrapa Pecuária Sudeste. No balanço hídrico climático foi considerada uma CAD de $100 \mathrm{~mm}$.

Mineirão e cv. Bandeirantes, 0,3 g/m, sementes escarificadas com lixa), feijão-de-porco (Canavalia ensiformis, $5 \mathrm{sem} . / \mathrm{m}$ ), mucuna-anã (Mucuna deeringeana, $10 \mathrm{sem} . / \mathrm{m}$ ), mucuna-preta (Mucuna aterrima, $5 \mathrm{sem} . / \mathrm{m}$ ), mucuna-cinza (Mucuna cinerea, $5 \mathrm{sem} . / \mathrm{m}$ ), crotalária (Crotalariajuncea, $1,2 \mathrm{~g} / \mathrm{m}$, Crotalaria spectabilis e Crotalaria breviflora, $0,6 \mathrm{~g} / \mathrm{m})$, leucena (Leucaena leucocephala, cv. Cunningham, $1 \mathrm{~g} / \mathrm{m}$, sementes escarificadas com ácido sulfúrico conc., durante $40 \mathrm{~min}$ ), soja (Glycine max, cv. IAC8, cv. IAC-11, cv. IAC-15 e cv. Doko, 3 g/m), sorgo-forrageiro (Sorghum bicolor, cv. Contimel, 0,6 g/m), milheto (Penissetum americanum, comum, 0,5 g/m) e milho-híbrido 1 (Zea mays, Contimax 322, 2,5 g/m), no plantio de outono. No período $1993 / 94$ foram eliminados os materiais pouco promissores, sendo testados: labe-labe (Dolichus lablab, cv. Rongai, 
$3 \mathrm{~g} / \mathrm{m}$ ), guandu (Cajanus cajan, cv. Fava-larga, $3 \mathrm{~g} / \mathrm{m}$ ), estilosantes (Stylosanthes guianensis, cv. Mineirão, $0,3 \mathrm{~g} / \mathrm{m}$, sementes escarificadas com lixa), feijão-de-porco (Canavalia ensiformis, $5 \mathrm{sem} . \mathrm{m}$ ), mucunapreta (Mucuna aterrima, $5 \mathrm{sem} . / \mathrm{m}$ ), mucuna-cinza (Mucuna cinerea, 5 $\mathrm{sem} . / \mathrm{m}$ ), crotalária (Crotalaria juncea, $1,2 \mathrm{~g} / \mathrm{m}$, e Crotalaria paulina, $0,6 \mathrm{~g} / \mathrm{m}$ ), sorgo-forrageiro (Sorghum bicolor, cv. DK-9 10, da Braskalb, $0,6 \mathrm{~g} / \mathrm{m}$ ), milheto (Penissetum americanum, comum, $0,5 \mathrm{~g} / \mathrm{m}$ ), tremoço-branco (Lupinus albus, 6g/m), nabo-forrageiro (Raphanus sativus, comum, $0,6 \mathrm{~g} / \mathrm{m}$ ), milho variedade (Zea mays, cv. Maya lte XXXBP1, do IAC, 3,5 g/m), milho-híbrido (Zea mays, Contibrasil 133, $10 \mathrm{sem} . / \mathrm{m}$ ), girassol (Helianthus anuus, 1-comercial desconhecido, 2-comercial de capítulo grande, $3 \mathrm{~g} / \mathrm{m}$ ), tefrósia (Tefrosia candida, $1 \mathrm{~g} / \mathrm{m}$ ), feijão-bravo-do-ceará (Canavalia brasiliensis, $5 \mathrm{sem} /$ m). No outono de 1995 foram testados: labe-labe (Dolichus lablab, cv. Rongai, $3 \mathrm{~g} / \mathrm{m}$ ), feijão-de-porco (Canavalia ensiformis, $5 \mathrm{sem} . /$ $\mathrm{m}$ ), mucuna-preta (Mucuna aterrima, $5 \mathrm{sem} . / \mathrm{m}$ ), mucuna-cinza (Mucuna cinerea, $5 \mathrm{sem} . / \mathrm{m}$ ), crotaláia (Crotalaria juncea, 1,2 g/m, e Crotalaria paulina, 0,6 g/m), sorgo-forrageiro (Sorghum bicolor, cv. DK-9 10, da Braskalb, 0,6 g/m), milheto (Penissetum americanum, comum, 0,5 g/m), tremoço-branco (Lupinus albus, $6 \mathrm{~g} / \mathrm{m}$ ), naboforrageiro (Raphanus sativus, comum, $0,6 \mathrm{~g} / \mathrm{m}$ ), milho variedade (Zea mays, cv. Maya lte XXXBP1, do IAC, 3,5 g/m), milho-híbrido (Zea mays, Agroceres 105, 2,5 g/m), girassol (Helianthus annus, IAC cv. Uruguay, 1 - comercial desconhecido, e 2 - comercial de capítulo grande, $3 \mathrm{~g} / \mathrm{m}$ ) e aveia-preta (Avena strigosa, comum, 1,6 g/m). A alteração das espécies testadas ao longo dos experimentos baseou-se no descarte de materiais sem potencial para atender o objetivo do projeto.

O espaçamento utilizado em $1992 / 93$ foi o de $0,50 \mathrm{~m}$, sendo 0,25 $\mathrm{m}$ para milheto, de acordo com recomendação. A área útil de cada parcela foi de 2,25 m². Em 1993/94 e 1995 o espaçamento utilizado foi o de $0,30 \mathrm{~m}$, para equiparar todas as espécies ao espaçamento recomendado ao milheto. A área útil de cada subparcela foi de $2,85 \mathrm{~m}^{2}$. $\mathrm{O}$ corte foi realizado a $0,10 \mathrm{~m}$ do solo.

Usaram-se três blocos ao acaso, em ambos os solos, ocorrendo o 
estabelecimento de parcelas emparelhadas no caso do teste da cobertura morta, num esquema semelhante ao de parcelas subdivididas. Para as espécies de florescimento atrasado estabeleceu-se parcela à parte para permitir verificar a produção final. $\mathrm{Na}$ análise de variância os dados de produção de matéria seca por hectare, foi empregado o teste $\mathrm{F}$ e, nas comparações de médias, o teste de Tukey ao nível de $5 \%$.

\section{a) Plantio no Verão}

No período 1992/93, o plantio ocorreu em 03/12/92, e a colheita 90 dias após (08/03/93), período disponível para permitir o estabelecimento de cultura safrinha. No período 1993/94, o plantio ocorreu em 29/ 11/93, e a colheita principal 95 dias após (04/03/94).

\section{b) Plantio no Outono}

No ano de 1993, o plantio ocorreu em 09/03/93, e a colheita em 30/06/93, 113 dias após. Procurou-se estender ao máximo o período vegetativo, a fim de permitir maior acúmulo de matéria seca, de forma comparável no tempo, do maior número de espécies. Houve rebrota do plantio no verão de labe-labe, crotalária-spectabilis e crotalária-breviflora, guandu, estilosantes, leucena, mucuna-preta, feijão-de-porco, sorgo-forrageiro e milheto, não considerados. No ano de 1994, o plantio ocorreu em 17/03/94, e a colheita principal em 25/ 05/94, 69 dias após. Nesta ocasião estavam florescidos o milheto, o milho variedade, a crotalária-juncea, o girassol, o tremoço, o naboforrageiro e o labe-labe. O corte ao florescimento do feijão-de-porco ocorreu 91 dias após plantio (16/6/94), do guandu e da crotaláriapaulina aos 116 dias (11/7/94), e das mucunas aos 175 dias (8/9/94). Ocorreu rebrota do plantio no verão de labelabe, crotalária-espectabilis e crotalária-breviflora, guandu, estilosantes, leucena, sorgo-forrageiro e milheto, não considerados neste trabalho. No outono de 1995 , o plantio ocorreu em 15/3/95, e a colheita principal 96 dias após (19/6/ 95). O florescimento de milho híbrido, milho-Maya, erotalária-paulina, tremoço, girassol Uruguay e girassol-2 aos 134 dias após semeadura (27/07/95) e da mucuna preta em 30/08/95 (168 dias). 


\section{RESULTADOS E DISCUSSÃO}

\section{a) Plantio no verão}

No período 1992/93, foram colhidos o millieto, o girassol, o tremoço e o naboforrageiro aos 72 dias (9/2/94) pois já estavam florescidos. Nesta ocasião estavam em início de florescimento o sorgo-forrageiro, o feijão-de-porco, a crotalária-juncea. Por ocasião da colheita prevista (90 dias pós-plantio) a soja apresentava vagens, o feijão-de-porco, a mucuna-anã, as crotalárias breviflora e spectabilis estavam em pleno florescimento, e o sorgo-forrageiro estava emitindo panícula. $O$ corte ao florescimento do guandu e da crotalária-paulina ocorreu aos 150 dias (28/4/94), do estilosantes aos 177 dias (25/5/94) e da tefrósia aos 276 dias $(1 / 9 / 94)$.

Verificou-se (Tabela 5) que a produtividade maior pertenceu ao milheto, destacando-se a mucuna-cinza entre as leguminosas. Estes materiais pareceram mostrar grande estabilidade na produção quanto à variação de fertilidade do solo, considerando-se também a maior fertilidade natural e capacidade de troca catiônica do LVd.

Embora tenha sido perdido o bloco que apresentava menor fertilidade no LVAa, pode ser observada a grande sensibilidade da crotaláriajuncea e do sorgoforrageiro à baixa fertilidade, devido à sua morte dez dias após a emergência, sugerindo a necessidade de se estabelecer nível mínimo de fertilidade para obter o máximo de produção de biomassa, podendo-se pensar em adubar os adubos verdes e reduzir a adubação da zultura principal para garantir maior produtividade do sistema de produão. Considerando a tendência de variação da produção de matéria seca, 1os dois solos, e os níveis de fertilidade nos blocos, as espécies poderiam ier enquadradas como de pouca tolerância à baixa fertilidade química do solo (foram melhores na saturação por bases em torno de $75 \%$ : milho, ;orgo-forrageiro, labe-labe, crotalária juncea e leucena), de média toleância (saturação por bases em torno de 50\%: feijãode-porco, mucunainza e crotaláia spectabilis) e de elevada tolerância (produziram razoarelmente na saturação por bases em torno de $25 \%$ : mucuna-preta e nilheto). 
Tabela 5. Produção de matéria seca (t/ha) dos materiais testados no verão.

\begin{tabular}{|c|c|c|c|c|c|c|c|c|c|c|c|c|}
\hline \multirow[t]{3}{*}{ Espẻcie } & \multicolumn{4}{|c|}{--1992/93 -..-- } & & \multicolumn{7}{|c|}{ 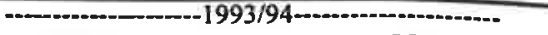 } \\
\hline & \multirow{2}{*}{\multicolumn{2}{|c|}{ LVAa }} & \multirow{2}{*}{\multicolumn{2}{|c|}{ LVd }} & \multicolumn{4}{|c|}{ 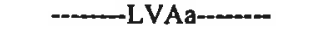 } & \multicolumn{4}{|c|}{-------LVd----....- } \\
\hline & & & & & \multicolumn{2}{|c|}{ sem } & \multicolumn{2}{|c|}{ com } & \multicolumn{2}{|c|}{ sem } & \multicolumn{2}{|c|}{ com } \\
\hline Labe-labe & 4,6 & bc & 5,6 & bc & 3,8 & cdA & 1,7 & $\mathrm{~dB}$ & 5,0 & cde & - & \\
\hline Mucuna-preta & 3,8 & bc & 2,8 & cd & 4,3 & cd & - & & 3,1 & de & - & \\
\hline Mucuna-cinza & 5,6 & b & 9,1 & b & 5,9 & bc & - & & 4,9 & cde & - & \\
\hline Feijao-de-porco & 3,1 & bc & 4,6 & cd & 5,0 & $\operatorname{cd} A$ & 4,0 & $\mathrm{cdB}$ & 4,4 & cde & 4,7 & bed \\
\hline Crotalária-juncea & 0,9 & c & 6,4 & bc & 6,0 & bed & 5,9 & cd & 8,3 & cd & 7,5 & bc \\
\hline Crotalária-paulina & - & & - & & 4,8 & cdA & 4,4 & $\mathrm{cdB}$ & 5,2 & cdeA & 3,1 & cdB \\
\hline (ao florescimento) & - & & - & & 17,7 & & 16,1 & & 17,3 & & 10,2 & \\
\hline Sorgo-forrageiro & 0,9 & c & 9,0 & b & 12,9 & a & 12,8 & ab & 27,9 & aA & 25,8 & aB \\
\hline Milheto & 18,5 & a & 18,9 & a & 7,7 & $a b c A$ & 7,3 & bcdB & 9,4 & c & 9,0 & b \\
\hline Milho variedade & - & & - & & 11,6 & $\mathrm{abB}$ & 14,7 & aA & 19,3 & bB & 23,0 & $\mathbf{a A}$ \\
\hline Milho-híbrido I & - & & - & & 7,7 & $a b c B$ & 9,9 & $a b c A$ & 22,4 & b & 23,7 & $\mathbf{a}$ \\
\hline Tremb́ço & - & & - & & 1,0 & $\mathrm{~dB}$ & 1,9 & dA & 0,5 & e & 1,0 & d \\
\hline Nabo-forrageiro & - & & - & & 3,2 & $\mathrm{cdB}$ & 3,7 & $\operatorname{cdA}$ & 3,5 & de & 3,9 & bed \\
\hline Girassol-A & - & & - & & 2,4 & ed & 2,6 & d & 4,1 & cde & 5,2 & bc \\
\hline Feijăo-bravo-ceará & - & & - & & 4,8 & cd & - & & 3,1 & de & - & \\
\hline Estilosantes Mine. & 0,3 & c & 0,6 & d & 1,0 & d & 1,1 & d & - & & - & \\
\hline (ao florecimento) & - & & - & & 2,8 & & 3,2 & & - & & - & \\
\hline Tefrósia & - & & - & & 1,6 & cd & 1,5 & d & 1,0 & e & 1,0 & d \\
\hline (ao florescimento) & - & & - & & 12,8 & & 9,4 & & - & & - & \\
\hline Guandu, F.larga) & - & & - & & 2,7 & $\mathrm{cdB}$ & 4,2 & $\operatorname{cdA}$ & 4,8 & cde & 3,8 & bed \\
\hline (ao florescimento) & $=$ & & - & & 10,7 & & 17,1 & & - & & - & \\
\hline Guandu, E.1822 & 1,6 & bc & 2,4 & cd & - & & - & & - & & - & \\
\hline Guandu, E.1679 & 1,9 & bc & 3,2 & cd & - & & - & & - & & - & \\
\hline Leucena & - & & 0,5 & d & - & & - & & - & & - & \\
\hline Mucuna-ană & 2,7 & bc & 4,0 & cd & - & & - & & - & & - & \\
\hline Soja, IAC-8 & 2,0 & bc & 3,1 & cd & - & & - & & - & & - & \\
\hline Soja, IAC-11 & 2,3 & bc & 2,6 & cd & - & & - & & - & & - & \\
\hline Soja, IAC-15 & 2,1 & bc & 4,0 & cd & - & & - & & - & & - & \\
\hline Soja, Doko & 2,3 & bc & 3,8 & cd & - & & - & & - & & - & \\
\hline Crotalária-espect. & 1,7 & bc & 3,0 & cd & - & & - & & - & & - & \\
\hline Crotalária-brevif. & 1,6 & be & 2,9 & cd & - & & - & & - & & - & \\
\hline Estilosantes Band. & 0,2 & c & 0,8 & d & - & & - & & - & & - & \\
\hline dms tratamentos & 3,6 & & 3,4 & & 6,3 & & 6,3 & & 5,3 & & 5,3 & \\
\hline dms cobertura & & & & & 0,3 & & 0,3 & & 1,3 & & 1,3 & \\
\hline
\end{tabular}

Médias, da colheita principal, nas colunas, seguidas de mesmas letras minúsculas, não diferem entre si (Tukey, $\mathrm{P}>0,05$ ). Letras maiúsculas diferentes nas linhas indicam diferenças entre cobertura de solo $(\mathrm{P}<0,05)$.

$\mathrm{Sem} / \mathrm{com}=$ cobertura morta (ao florescimento) $=$ corte das parcelas em separado, das espécies que floresceram após a data preestabelecida de colheita principal. 
Como esperado, o estilosantes e a leucena apresentaram produçóes baixas devido ao seu crescimento inicial lento. O guandu surpreendeu por alcançar produções comparáveis à da soja.

No período $1993 / 94$, por ocasião da colheita predeterminada (95 dias) do plantio de verão, em 4/3/94, o sorgo-forrageiro, o feijão-de-porco e a crotalária-juncea estavam florescendo. E já haviam sido colhidos em 9/2/94 (aos 72 dias) o milheto, o girassol-1, o tremoço e o naboforrageiro, que em 31/1/94 (aos 63 dias) apresentavam um grau de florescimento de, respectivamente, 10, 50, 80 e $90 \%$.

Em ambos os solos a crotalária-paulina e o guandu apresentaram uma produção elevada de matéria seca ao florescimento, chegando a ser maior que a das gramíneas no LVAa (Tabela 5).

No LVd, mesmo com perda do bloco de menor fertilidade, a média de produção maior coube às gramíneas sorgo-forrageiro e milho-híbrido, tanto em solo sem como com cobertura morta. Também foi prejudicada a colheita da subparcela com cobertura morta das leguminosas rasteiras. A cobertura morta em geral apresentou a tendência de efeitos negativos sobre as leguminosas, com excessão do tremoço, bem como efeitos positivos sobre o milho, o girassol, o nabo-forrageiro e o guandu. Verificando-se a produção de matéria seca entre os blocos com níveis diferentes de fertilidade, parecem apresentar maior exigência o tremoço, a mucunacinza (a mucuna-preta menos exigente), a crotalária-paulina, o guandu, o milheto, o milho-híbrido, o feijão-bravo-do-ceará. No LVAa verificou-se um quadro de resposta em geral semelhante, acentuando-se a resposta ao nível de fertilidade mais adequado, ocorrendo resposta ao bloco com maior nível de fertilidade pelo labe-labe, feij ão-de-porco, crotalária-paulina, nabo-forrageiro e milheto, com média fertilidade pela mucuna-cinza. crotaláia-juncea, guandu, tefrósia, tremoço, sorgoforrageiro, milhoMaya, milho-híbrido e estilosantes, e indiferente a mucuna-preta. Estas verificações deverão ser confirmadas em experimentos específicos de fertilidade do solo.

\section{b) Plantio no outono}

No ano de 1993, o milheto iniciou emissão de panícula em 13/5/ 
93. A crotalária-juncea iniciou florescimento em 7/5/93, o sorgo-forrageiro e as crotalárias breviflora e spectabilis em 13/5/93.

Verificou-se (Tabela 6) que a produtividade maior pertenceu ao milho híbrido, destacando-se a mucuna-cinza entre as leguminosas, no LVd. Não houve diferenças no LVAa, embora as produçôes de matéria seca das mucunas e do milho tenderam a ser melhores.

O bloco de fertilidade menor no LVAa foi perdido, não havendo desenvolvimento da crotalária-breviflora em ambos os solos e de sorgoforrageiro no LVAa. Pode ser constatada a grande sensibilidade da crotalária-juncea, do sorgoforrageiro e do milho à baixa fertilidade, devido à sua morte logo após a emergência.

Verificou-se uma grande defasagem de produção das espécies no plantio do outono, com maior estabilidade para a mucuna-preta, embora ainda sobrepujada pela mucuna-cinza, mas com produção de matéria seca insuficiente para atingir as $6 \mathrm{t} / \mathrm{ha}$ mínimas necessárias para a proteção da superfície do solo. Parece que as gramíneas, especialmente o milho, adequadas ao menor fotoperíodo, possuem maior potencial para atender esta demanda.

De maneira geral os adubos verdes parecem exigir um nível mínimo de fertilidade do solo, em geral entre 50 e $75 \%$ de saturação por bases. Foi verificado que no bloco 3, com maior fertilidade, as gramíneas apresentaram-se mais vigorosas, sem mostrar carência visual de N, especialmente no LVd. O que pode ser explicado pelo melhor ambiente químico no solo, para a atividade biológica, e a mineralização de material orgânico.

Considerando os resultados do plantio de março e os dados levantados em área adjacente maior, parece que as gramíneas teriam maior potencial, bem como eventualmente a mucuna, se deixada até o início da primavera, quando parece ocorrer seu florescimento. Também o girassol e outras espécies de inverno deveriam ser testados. Verificou-se a necessidade de realizar, além do corte com data pré-estabelecida, cortes ao florescimento para uma avaliação mais justa das espécies de ciclo curto e longo.

No ano de 1994, o plantio do outono, em ambos os solos, mostrou 
Tabela 6. Produção média de matéria seca (t/ha) dos materiais testados no outono.

\begin{tabular}{|c|c|c|c|c|c|c|c|c|c|c|c|c|}
\hline \multirow[t]{3}{*}{ Espécie } & \multicolumn{4}{|c|}{ 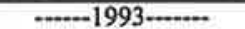 } & & \multicolumn{7}{|c|}{ 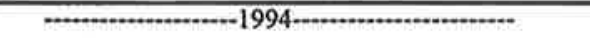 } \\
\hline & \multirow{2}{*}{\multicolumn{2}{|c|}{ LVAa }} & \multirow{2}{*}{\multicolumn{2}{|c|}{ LVd }} & \multicolumn{4}{|c|}{-LVAa-_- } & \multicolumn{4}{|c|}{-.._-_L_L LV } \\
\hline & & & & & & sem & & com & se & m & & $\operatorname{com}$ \\
\hline Labe-Jabe & 0,0 & $\mathbf{a}$ & 2,4 & bcad & 0,8 & fgA & 0,1 & $\mathrm{hB}$ & 0,2 & fB & 0,9 & $\mathrm{fgA}$ \\
\hline Mucuna-preta & 1,2 & a & 2,9 & bc & 1,2 & efgB & 1,6 & fghA & 0,8 & efA & 0,5 & fgB \\
\hline (ao florescimento) & - & & - & & 3,5 & & 4,7 & & - & & - & \\
\hline Mucuna-cinza & 1,3 & a & 3,8 & b & 1,8 & defg & 1,7 & efgh & 1,0 & ef & 1,1 & $\mathrm{fgA}$ \\
\hline (ao florescimento) & - & & - & & 4,3 & & 3,9 & & - & & - & \\
\hline Feijzo-de-porco & 0,4 & $\mathbf{a}$ & 1,7 & cdef & 1,9 & cdefg & 1,8 & defg & 2,0 & $\operatorname{cdeA}$ & 1,5 & efgB \\
\hline (ao florescimento) & - & & - & & 2,4 & & 3,2 & & - & & - & \\
\hline Crotalária-juncea & 0,3 & $\mathbf{a}$ & 2,0 & bede & 2,4 & bcdefA & 1,8 & $\operatorname{defgB}$ & 2,1 & cdeA & 1,6 & $\operatorname{defg} B$ \\
\hline Crotalária-paulina & - & & - & & 0,8 & $\mathrm{fgA}$ & 0,4 & ghB & 0,5 & efA & 0,3 & gB \\
\hline (ao florescimento) & - & & - & & 2,3 & & 1,6 & & 2,3 & & 1,2 & \\
\hline Sorgo-forrageiro & 0,0 & & 0,8 & def & 3,7 & bA & 3,4 & bcdB & 3,4 & $\mathrm{bcA}$ & 0,9 & $\mathrm{fgB}$ \\
\hline Milheto & 0,5 & a & 3,1 & bc & 5,7 & aA & 5,1 & $\mathbf{a B}$ & 3,9 & $a b A$ & 2,0 & cdefB \\
\hline Milho variedade & - & & - & & 3,2 & bcdB & 4,0 & abcA & 3,6 & bc & 3,5 & $a b c$ \\
\hline Milho-hibrido-2 & - & & - & & 3,1 & bcdB & 4,6 & $\mathrm{abA}$ & 5,4 & aA & 4,8 & $\mathrm{aB}$ \\
\hline Tremóço & - & & - & & 1,0 & $\mathrm{fg}$ & 0,9 & fgh & 1,7 & $\operatorname{def} A$ & 1,2 & $\mathrm{fgB}$ \\
\hline Nabo-forrageiro & - & & - & & 2,7 & bcdeB & 3,4 & bcdA & 3,1 & bcd & 3,2 & abcd \\
\hline Girassol-A & - & & - & & 3,0 & bcdA & 2,5 & cdeB & 3,6 & bcA & 3,0 & bcdeB \\
\hline Girassol-B & - & & - & & 3,5 & bcA & 3,3 & bcdeB & 4,3 & $\mathrm{abA}$ & 4,0 & $a b B$ \\
\hline (ao florescimento) & - & & - & & 6,4 & & 7,1 & & 11,5 & & 8,3 & \\
\hline Tefrósia & - & & - & & 0,3 & $\mathbf{g}$ & 0,2 & gh & 0,0 & $\mathbf{g}$ & 0,0 & $\mathrm{~g}$ \\
\hline Guandu, F.larga) & - & & - & & 0,3 & $\mathrm{gB}$ & 0,5 & ghA & 0,1 & $\mathrm{f}$ & 0,1 & $\mathrm{~g}$ \\
\hline (ao florescimento) & - & & - & & 1,1 & & 1,0 & & - & & - & \\
\hline Guandu, E.1822 & 0,3 & a & 0,6 & def & - & & - & & - & & - & \\
\hline Guandu, E.1679 & 0,4 & a & 0,6 & def & - & & - & & - & & - & \\
\hline Leucena & - & & 0,1 & f & - & & - & & - & & - & \\
\hline Milho hibrido-1 & 1,2 & a & 11,0 & $\mathbf{a}$ & - & & - & & - & & - & \\
\hline Soja, IAC-8 & 0,3 & a & 1,4 & cdef & - & & - & & - & & - & \\
\hline Soja, IAC-1 I & 0,4 & $\mathbf{a}$ & 0,6 & def & - & & - & & - & & - & \\
\hline Soja, IAC-15 & 0,4 & a & 1,6 & cdef & - & & - & & - & & - & \\
\hline Soja, Doko & 0,4 & a & 0,9 & def & - & & - & & - & & - & \\
\hline Crotalária-espectabil. & 0,2 & a & 0,3 & ef & - & & - & & - & & - & \\
\hline Estilosantes-Mineirăo & 0,4 & a & 0,7 & def & - & & - & & - & & - & \\
\hline Estilosantes-Bandeir. & 0,1 & a & 0,5 & ef & - & & - & & - & & - & \\
\hline dms tratamentos & 1,4 & & 1,8 & & 1,6 & & 1,6 & & 1,6 & & 1,6 & \\
\hline dms cobertura & & & & & 0,2 & & 0,2 & & 0,2 & & 0,2 & \\
\hline
\end{tabular}

Médias, da colheita principal, nas colunas, seguidas de mesmas letras minúsculas não diferem entre si (Tukey, $\mathrm{P}>0,05$ ). Letras maiúsculas diferentes, nas linhas, indicam diferenças entre cobertura de solo $(\mathrm{P}<0,05)$.

$\mathrm{Sem} / \mathrm{com}=$ cobertura morta ( ao florescimento $)=$ corte das parcelas em separado, das espécies que floresceram após a data preestabelecida de colheita principal. 
menor acúmulo de matéria seca, determinado em corte pré-determinado de 69 dias, e ao florescimento, à excessão das espécies de inverno tremoço, nabo-forrageiro e girassol. O feijão-de-porco e o milheto sofreram uma redução menor. A produção maior de matéria-seca foi obtida pelo girassol-2 ao florescimento. Surgiu o alerta para a necessidade de testar variedades e espécies diferentes. No LVAa a maior produção próxima das $6 \mathrm{t} / \mathrm{ha}$ coube ao milheto e no LVd ao milho híbrido. Ficou ainda a preocupação de se procurar colher 6 t/ha de matéria seca equivalente milho (promove maior cobertura de solo que uma massa equivalente de leguminosas).

Foi verificado em área maior adjacente, que o tremoço, por apresentar crescimento indeterminado, pode acumular muito mais massa seca quando vegetar por período mais prolongado, até o início do secamento das folhas apicais, o que deve ser confirmado futuramente.

Em 28/06/94 ocorreu geada, que não afetou a crotalária-paulina, o guandu, a tefrósia e a leucena (área adjacente). A geada afetou mais intensamente as folhas de feijão-de-porco, labe-labe e as mucunas.

No outono de 1995, aos 69 dias houve início de florescimento da crotalária júncea, tremoço, milheto, sorgo-forrageiro, aveia, naboforrageiro, e girassol-1, ocorrendo acamamento deste último. A colheita principal ocorreu aos 96 dias, e o corte ao florescimento pleno de milhohíbrido, milho-Maya, crotalária-paulina, tremoço, girassol Uruguay e girassol-2 aos 134 dias e da mucuna-preta 168 dias após a semeadura. As mucunas iniciaram florescimento em 27/7/95.

As produções de aveia-preta e nabo-forrageiro concordaram e os de tremoço estão um pouco abaixo dos resultados obtidos por Pitol (1993). $\mathrm{O}$ resultado do tremoço (Tabela 7) parece ter sido afetado por temperaturas e déficit hídrico mais elevados durante seu ciclo em 1995 (Tabela 4), pois esperava-se produtividade bem maior sem cobertura morta. As produtividades de aveia-preta, nabo-forrageiro e tremoço-branco coincidiram com as citadas por Derpsch (1984), sendo que a produção de girassol foi superior em São Carlos. A produtividade de matéria seca de adubos verdes apresentadas por Burle et al. (1992), apesar de ter sido considerado um período maior de vegetação, foram em princípio menores que 
Tabela 7. Produção média de matéria seca (t/ha) dos materiais testados no outono de 1995.

\begin{tabular}{|c|c|c|c|c|c|c|}
\hline \multirow[t]{2}{*}{ Espécie } & \multicolumn{2}{|c|}{ 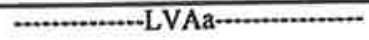 } & \multicolumn{4}{|c|}{ 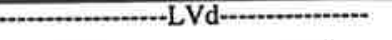 } \\
\hline & sem & com & sem & & con & \\
\hline Labe-labe & 4,7 deA & 3,5 cdB & 2,9 & bc & 2,8 & de \\
\hline Mucuna-preta & $2,7 \mathrm{e}$ & 3,6 cd & 2,9 & bcA & 1,3 & fB \\
\hline (ao florescimento) & 7,6 & 7,1 & 11,3 & & 7,4 & \\
\hline Mucuna-cinza & $3,9 \mathrm{de}$ & 4,5 bed & 2,2 & cB & 4,5 & cdeA \\
\hline (ao florescimento) & 6,5 & 10,2 & 9,2 & & 12,2 & \\
\hline Feijăo-de-porco & 3,4 deB & 4,5 bedA & 3,8 & $b c$ & 3,8 & def \\
\hline Crotalária-juncea & $3,5 \mathrm{deB}$ & 6,0 bcdA & 3,9 & bcB & 5,4 & cdeA \\
\hline Crotalária-paulina & $2,3 \mathrm{e}$ & $1,4 \mathrm{~d}$ & 2,0 & c & 1,6 & ef \\
\hline (ao florescimento) & 5,3 & 4,5 & 5,5 & & 3,7 & \\
\hline Sorgo-forrageiro & 3,9 de & $3,2 \mathrm{~cd}$ & 4,9 & $b c B$ & 6,9 & $\operatorname{cdA}$ \\
\hline Milheto & $6,9 \mathrm{cdA}$ & 5,1 bcdB & 4,3 & beB & 5,4 & efA \\
\hline Milho Maya & $9,8 \mathrm{bcB}$ & $11,0 \mathrm{abA}$ & 10,0 & $\mathrm{aB}$ & 13,8 & bA \\
\hline (ao florescimento) & 7,0 & 8,9 & 9,3 & & 13,2 & \\
\hline Milho-hfbrido-2 & $5,4 \mathrm{deB}$ & 7,4 bA & 9,2 & $\mathrm{aB}$ & 12,9 & bA \\
\hline (ao florescimento) & 8,8 & 10,7 & 12,2 & & 14,3 & \\
\hline Tremóço-branco & 1,9 e & $1,9 \mathrm{~d}$ & 2,3 & cA & 1,5 & efB \\
\hline (ao florescimento) & 2,9 & 3,5 & 1,5 & & 6,7 & \\
\hline Nabo-forrageiro & 4,5 deB & $6,6 \mathrm{bcA}$ & 4,6 & $\mathrm{bcB}$ & 7,0 & $\mathbf{c A}$ \\
\hline (raiz) & - & - & 1,6 & & 2,5 & \\
\hline Girassol-1 & 14,2 a & 14,1 a & 11,1 & $\mathbf{a B}$ & 12,2 & bA \\
\hline Girassol-2 & 11,9 abB & 13,0 aA & 11,3 & $\mathrm{aB}$ & 19,1 & aA \\
\hline (ao florescimento) & - & - & 4,6 & & 16,0 & \\
\hline Girassol Uruguay & $9,8 \mathrm{bcB}$ & 12,7 aA & 11,2 & $\mathbf{a B}$ & 17,2 & $\mathbf{a A}$ \\
\hline (ao florescimento) & - & - & 20,4 & & 6,3 & \\
\hline Aveia-preta & $3,5 \mathrm{de}$ & 4,1 bcd & 5,5 & bB & 6,7 & cdA \\
\hline dms tratamentos & 3,7 & 3,7 & 3,0 & & 3,0 & \\
\hline dms cobertura & 0,9 & 0,9 & 0,5 & & 0,5 & \\
\hline
\end{tabular}

Médias, da colheita principal, nas colunas, seguidas de mesmas letras minúsculas não diferem entre si (Tukey, $\mathrm{P}>0,05$ ). Letras maiúsculas diferentes nas linhas indicam diferenças entre cobertura de solo $(\mathrm{P}<0,05)$.

$\mathrm{Sem} / \mathrm{com}=$ cobertura morta. (ao florescimento) $=$ corte das parcelas em separado, das espécies que floresceram após a data a de colheita principal.

as obtidas em São Carlos, talvez devido ao espaçamento adotado, ou ao manejo adotado para elevar a fertilidade do solo ao nível médio.

Foi confirmado (Tabela 7) o potencial de produção do girassol e do milho, despontando o nabo-forrageiro com relação ao tremoço, bem como a possibilidade de boa produção de biomassa das mucunas, desde que fosse dado o tempo devido de desenvolvimento e não ocorressem 
geadas fortes. Para estas espécies, a cobertura morta mostrou ser uma prática que pode melhorar os resultados de produção, exceto para mucunapreta. Foi visível a superioridade das gramíneas, na produção de matéria seca para cobertura morta do solo, com relação às leguminosas e ao girassol, que concentram a matéria seca nos talos e frutos.

Atualmente têm surgido outras opções de cobertura do solo para plantio direto de milho ou sorgo para silagem, como a utilização de guandu selecionado no Estado do Mato Grosso do Sul, para plantio em março, e do milheto de origem africana, além da integração, durante um ano, com pastagens de braquiária (Cabezas \& Freitas, 2000) ou o estabelecimento de uma cobertura permanente de Arachis pintoi (amendoim-forrageiro), opções que deverão ser testadas, além do estudo mais detalhado de níveis de fertilidade do solo em que os adubos verdes manifestam sua maior produtividade. Os dados preliminares sugerem que a maioria dos adubos verdes reage bem a um nível médio a alto de fertilidade, o que leva a concluir que seria uma estratégia aconselhável manter ou mesmo reduzir a adubação da cultura principal, porém estimular a produção de biomassa do adubo verde, o que deverá gerar reflexos positivos sobre a cultura principal, e assim ao sistema de produção como um todo, ao longo do ano agrícola.

\section{CONCLUSÕES}

1) No plantio de março as gramíneas parecem apresentar potencial maior na produção desejável de matéria seca para a cobertura de solo que as leguminosas.

2) As leguminosas plantadas em março e cortadas com 113 dias apresentaram no máximo $50 \%$ do mínimo requerido ( 6 t/ha) de matéria seca para a cobertura morta do solo.

3) Deve ser considerado o tipo de solo, o nível de fertilidade e a cobertura morta na avaliação de espécies vegetais.

4) A cobertura morta do solo, no plantio de março, pode trazer beneficio à produção de milho, girassol, nabo-forrageiro, tremoço-branco e mucuna-cinza, dependendo do tipo de solo. 
5) Mais estudos necessitam ser realizados para a avaliação adequada dos adubos verdes e de opções de manejo de cobertura do solo para otimizar áreas de produção de milho para silagem em plantio direto abaixo do paralelo 23 .

\section{AGRADECIMENTOS}

Desejamos ressaltar nossos agradecimentos aos colegas Engo. Agro. José A. Donizeti Carlos, da Pirai Sementes, Piracicaba, SP, pelo fonecimento de sugestões e de sementes de leguminosas; Dra. Sonia F.Dechen, da Seção de Conservação de Solos do Instituto Agronômico, Campinas, SP, pelas análises fisicas do solo; a Sementes Disolo, São Carlos, SP, pelo fornecimento de sementes de soja; à Dra. Regina Ungaro da Seção de Oleaginosas e ao Dr. Luiz Eugênio Coelho de Miranda da Seção de Milho e Cereais Diversos do Instituto Agronômico, Campinas, SP, pelo fornecimento de sementes de girassol e milho, respectivamente.

\section{REFERENCIAS BIBLIOGRÁFICAS}

ABBOUD, A.C.S.; DUQUE, F.F. 1993. Caracterização de Leguminosas com Potencial para Produção Verde no Período da Seca. In. CONGRESSO BRASILEIRO DE CIÊNCIA DO SOLO, 24., Goiânia. Resumos. vol.3. Goiânia: Sociedade Brasileira de Ciência do Solo. p.99-100.

AMABILE, R.F.; CARVALHO, A M de; DUARTE, J.B.; FREITAS, P.L. de. 1993. Avaliação da Época de Semeadura e do Espaçamento de Diferentes Espécies de Leguminosas na Região dos Cerrados. In: CONGRESSO BRASILEIRO DE CIÊNCIA DO SOLO, 24., Goiânia. Resumos. vol.3. Goiânia: Sociedade Brasileira de Ciência do Solo. p. 103-104.

BURLE, M.L.; SIJHET, A.R.; PEREIRA, J.; RESCK, D.V.S.; PERES,

J.R.R, CRAVO, M.S.; BOWEN, W.; BOULDIN, D.R., LATHWELL, D. J. 1992. Legume Green Manures: Dry Season Survival and 
the Effect on Succeeding Maize Crops. Raleight, North Carolina Sta.Univer. 35p. (Soil Management CRSP Bulletin, 92-04).

CABEZAS, W.A.R.L.; FREITAS, P.L. de. Plantio Direto na Integrado

Lavoura Pecuária. Uberlândia: APDP/Universidade Federal de Uberlândia, 2000.282p.

CASTRO, O.M. de. 1993. Sistemas Conservacionistas no Brasil - a Experiência no Estado de São Paulo. In: CONGRESSO BRASILEIRO DE CIÊNCIA DO SOLO, 24, Goiânia, 1993. Resumos. vol. 1. Goiânia, Sociedade Brasileira de Ciência do Solo. p.77-78. DERPSCH, R. 1984. Alguns Resultados sobre Adubação Verde no Paraná. In: $\mathrm{CNPq}$, coord., Adubação Verde no Brasil. Campinas: Fundação Cargill. p.268-279.

PITOL, C. 1993. Espécies Vegetais para Safrinha de Inverno Visando Cobertura do Solo. Maracaju, Fundação MS. 6p. (Informativo Técnico, 2/93).

RAIJ, B v., QUAGGIO, J.A.; CANTARELLA, H ; FERREIRA, M.E , LOPES, AS.; BATAGLIA, O.C. 1982. Análise Química do Solo para Fins de Fertilidade. Campinas, Fundação Cargill. 170p. SAS Institute. (1993). SAS/STAT User's Guide: Statistics. Release 6.4. Cary, SAS Inst. 1686p.

SCALEA, M.J. 1992. Cerrado: Plantio Direto. São Paulo, Monsanto. $14 \mathrm{p}$. 